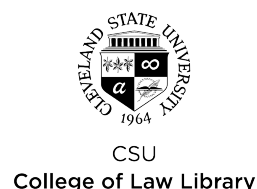

Cleveland State University

College of Law Library

\title{
EngagedScholarship@CSU
}

1995

\section{Rare Diseases, Drug Development and AIDS: The Impact of the Orphan Drug Act}

Michael Henry Davis

Cleveland State University, m.davis@csuohio.edu

Peter S. Arno

Karen Bonuck

Follow this and additional works at: https://engagedscholarship.csuohio.edu/fac_articles

Part of the Food and Drug Law Commons, and the Health Law and Policy Commons

How does access to this work benefit you? Let us know!

Publisher's Statement

(C) 1995 The Milbank Memorial Fund.

Original Citation

Michael Henry Davis, Peter S. Arno and Karen Bonuck, Rare Diseases, Drug Development and AIDS: The Impact of the Orphan Drug Act, 73 Milbank Quarterly 231 (1995)

This Article is brought to you for free and open access by the Faculty Scholarship at EngagedScholarship@CSU. It has been accepted for inclusion in Law Faculty Articles and Essays by an authorized administrator of EngagedScholarship@CSU. For more information, please contact research.services@law.csuohio.edu. 


\title{
Rare Diseases, Drug Development, and AIDS: The Impact of the Orphan Drug Act
}

\author{
PETER S. ARNO, KAREN BONUCK, \\ and MICHAEL DAVIS \\ Montefiore Medical Center/Albert Einstein College of Medicine, \\ Bronx, New York; Clevland State University
}

The orphan Drug act, shepherded through Congress as a humanitarian measure and signed into law by

- President Reagan in 1983, was an historic attempt to stimulate the development of drugs for rare diseases. ${ }^{1}$ More than 20 million Americans suffer from one of the approximately 5,000 so-called orphan diseases, each afflicting small numbers of people and for which little or no effective pharmaceutical therapy has been available (Meyers 1991a).

In theory, the act is intended to help bring to the market drugs for diseases that the pharmaceutical industry might not otherwise have the financial incentives to pursue. Typically, drugs are orphaned because the potential market is considered too small, and thus unprofitable, to justify the research and development $(\mathrm{R} \& \mathrm{D})$ investment; because a product is not patentable; or because liability concerns arise stemming from the nature of the target population (e.g., pregnant women or children) (Scharf 1985). Both directly and indirectly, public monies are used to subsidize orphan drug development through a variety of tax credits, te-

${ }^{1}$ P.L. 97-414: 97th Cong, , 1st sess. (1983).

The Milbank Quarterly, Vol. 73, No. 2, 1995

(c) 1995 Milbank Memorial Fund. Published by Blackwell Publishers,

238 Main Street, Cambridge, MA 02142, USA, and 108 Cowley Road,

Oxford OX4 IJF, UK. 
search grants, and other subsidies. All drugs designated as orphans are eligible to receive the direct subsidies and to earn the act's most powerful incentive: the indirect subsidy achieved through seven years of exclusive marketing rights. Exclusivity, however, is awarded only to the first sponsor to win licensing rights from the Food and Drug Administration (FDA).

By some measures, the act has been a resounding success. During the 10 years before the law was enacted, only 10 orphan drugs were developed without government support (Asbury 1985). During the first decade after its enactment, 513 drugs were designated as orphans, 87 of which were licensed for sale by the FDA (Orphan Products Board 1993: personal communication, March 24). However, the extraordinary prices charged for some of these orphan products, and the blockbuster sales that have generated hundreds of millions of dollars for others, raise troubling questions for policy makers and the public that have led to considerable debate about the need to amend the act.

The development of drugs for AIDS has been inextricably linked with the Orphan Drug Act; their history highlights many of its strengths and weaknesses. In the early days of the epidemic, the absence of treatments was believed to be linked to the lack of commercial potential for treatment. Nineteen drugs have been licensed by the FDA to treat AIDS and HIV-related diseases (Food and Drug Administration 1994a); of these, 13 are designated orphan drugs and 10 have received exclusive marketing rights under the act (B. Hood, Orphan Products Board 1994: personal communication, June 27). In addition, approximately 70 drugs designated as orphans are being developed to treat HIV-related diseases (Food and Drug Administration 1994b).

In this article, we examine the Orphan Drug Act with an eye toward its contribution to the public interest, using AIDS drugs to illustrate many of the central points. The major policy question is, How, if at all, can the act be used to meet the legislative goal of stimulating drug development for small patient populations without resulting in prices that make drugs inaccessible?

\section{The History of the Orphan Drug Act}

Prior to the Orphan Drug Act, the pharmaceutical industry produced "public service" drugs, which had been proved safe and effective in pre. 
liminary clinical testing, but whose limited market value impeded commercialization (Van Woert 1978). A 1981 congressional survey found that only 20 percent of approved public service drugs resulted from research targeted specifically at a rare disease. Most of the rest were serendipitous discoveries or the outcome of research for nonorphan conditions (U.S. Congress 1982). This meant that a moderate additional investment would enable the industry to make its unexpected discoveries available while garnering goodwill with the public, the FDA, and the medical establishment.

Assurances made to a government task force by the Pharmaceutical Manufacturer's Association, the major trade group for American pharmaceutical companies, that industry was responding adequately to the need for public service drugs did not allay concern during the 1970 s. Two federal task forces were convened to study the issue, but were stymied by the absence of consensus between government and industry (Asbury 1985).

Much of the impetus for new legislation came instead from a grassroots consumer movement spearheaded by the National Organization for Rare Disorders that was founded as an informal coalition by Abbey Meyers in the late 1970s. In 1980, federal legislation was introduced to establish a pool of government grants to be used by drug companies for orphan drug development. The funds would be paid back once a manufacturer's drug revenues reached a prearranged level (Asbury 1985). However, the prevailing hands-off-industry climate of the Reagan administration thwarted this payback concept. Instead, perhaps seeing the possibility of even greater profits through a less closely policed mechanism, industry lobbied hard for economic incentives in exchange for its support, and the Orphan Drug Act became law early in 1983.

At that time, the act covered "any disease or condition that occurs so infrequently in the United States that there is no reasonable expectation that the cost of developing and making available a drug for such disease or condition will be recovered from sales in the United States of such drug." 2 To qualify for tax credits under the act, the Internal Revenue Service (IRS) required companies to submit financial data documenting limited profitability. Rather than be subject to financial scrutiny by the IRS, however, the pharmaceutical industry sought to base the definition of orphan diseases on the size of the affected patient population, rather 
than on profit levels. In 1984, an amendment was passed altering the definition of a rare disease or condition to one that:

(a) affects less than 200,000 persons in the United States or (b) affects more than 200,000 persons in the United States and for which there is no reasonable expectation that the cost of developing and making available a drug for such disease or condition will be recovered from sales in the United States of such drug. ${ }^{3}$

The 200,000-person threshold was arbitrarily determined by the observation that companies were unwilling to manufacture drugs for narcolepsy or multiple sclerosis, each believed to affect approximately 200,000 persons (Meyers 1991b). Not one sponsor had sought an orphan drug designation on the basis of the second criterion, presumably because it requires a sponsor to submit estimated development and production costs and to provide information about expected sales (Food and Drug Administration 1984; R. Steeves, Orphan Products Board 1991: personal communication, October 2).

In 1985 another amendment to the act removed the requirement that marketing exclusivity could only be bestowed on unpatentable drugs defined as those for which a U.S. Letter of Patent could not be issued. ${ }^{4}$ This original provision of the act was specifically meant to bring to market drugs that were not commercially viable because patent exclusivity could not be obtained for them. Establishing that a drug is definitely unpatentable, however, is difficult. It is difficult because patents may be issued to cover new processes, machines, manufacturers or composition of matter, or any novel, useful improvements upon them, including new uses for a drug. Because of the latitude given to patent coverage, lawmakers sought to clarify the act by passing the 1985 amendment; no procedure was adopted to address the possibility that a patent might later be granted. In this case, it could be argued that the 17 -year patent monopoly is a definably sufficient incentive to guarantee exploitation of the invention.

Nearly 10 years after the passage of Orphan Drug Act, in December 1992, the FDA finally issued formal regulations to codify administrative practices. ${ }^{5}$ For the most part, the regulations avoid the thorny, contro-

\footnotetext{
${ }^{3}$ P.L. 98-551. Health Promotion and Disease Prevention Amendments (1984).

${ }^{4}$ P.L. 99-91. Orphan Drug Amendments, 99th Cong., 2d sess. (1985).

${ }^{5}$ Federal Register, 21 CFR, pt. 316: dock. no. 85 N-04831 (December 29, 1992).
} 
versial issues that have prompted legislative proposals to amend the act. One significant development, however, is that the FDA has clarified its approach to the eventuality of another company seeking to market a product chemically similar to one that has been granted orphan drug exclusivity. The regulations bar approval of drugs with the same major molecular structure unless they are shown to be safer, more effective, or to provide some other major contribution to patient care.

The regulations' protection for sponsors of orphan drugs granted exclusivity is, paradoxically, potentially more valuable and generous than a patent owner might receive even through the "doctrine of equivalents" under patent law. Under this doctrine a second drug is the "same," and therefore infringing, only if it is literally either the same as the patent claim or substantially so. Conversely, compounds are different provided that they are not substantially the same (as measured by the precise and express language of the patent claims), although there need not be major differences between the two (Colton and Haas 1992). The emphasis, therefore, is not on how different they are, but on whether they are literally or substantially alike. In contrast, the FDA's regulations require the second drug to manifest "major" differences in order to avoid being the "same" as an existing orphan drug. The regulations, therefore, cast a wider net over what is considered an infringement by one sponsor upon another than does existing patent law.

\section{Incentives to Industry}

Marketing exclusivity is the most potent incentive offered by the Orphan Drug Act to manufacturers because many orphan products are drugs whose patents have expired, that are found in nature, or that consist of biotechnology products that duplicate substances normally found in nature, making them difficult to patent. In the absence of patent protection, a sponsor who develops and markets a drug has no way to safeguard against competition from literal copies. Even with a patent, however, a manufacturer - absent Orphan Drug privileges - always runs the normal competitive risk of other manufacturers introducing a "copy cat" drug (a drug that is not a literal copy but that differs minimally in both its chemical and clinical characteristics) that does not literally infringe a patented drug. In addition to the Orphan Drug Act, the pharmaceutical industry receives unique privileges in patent law. Alone among all patent 
owners, drug manufacturers and related industries are able to extend their patent beyond the 17-year term applicable to all others by up to five additional years. ${ }^{6}$

The possible or apparent absence of firm patent laws applicable to the lucrative and expanding biotechnology field, according to the drug industry, has created particular interest in orphan drug status. The marketing exclusivity provided by the act is one way for biotechnology drugs, which are difficult to patent because they are found in nature, to secure an exclusive market niche (Coster 1992). On the other hand, to suggest that patentability is ever certain is to deny the historical uncertainty that has always characterized patent law (Kalinchak 1994).

Once a drug is designated an orphan, its sponsors are also eligible for a tax credit. Originally, industry sought a 90 percent tax credit on expenses for clinical trials, but under pressure from the Treasury Department, the final legislation provided a 50 percent credit. Eligible expenses include human clinical research on orphan drugs, but exclude animal and laboratory research. The remaining 50 percent of costs may be considered a deductible business expense, providing a total tax liability reduction of approximately 70 percent (Asbury 1985). ${ }^{\text {? }}$

Research grants awarded on a competitive basis by the FDA for pivotal clinical trials provide an additional incentive for phatmaceutical firms to study orphan drugs. The grant program, which first requires qualifying applicants to complete preliminary research, has grown from $\$ 500,000$ in 1983 to $\$ 9,145,000$ in 1992 (Office of Orphan Products 1993: personal communication, July 7). Although the majority of these grants go to academic researchers, some have been awarded to small companies.

\section{The Weaknesses of the Orphan Drug Act}

Many industry practices have subverted the goals of the Orphan Drug Act, while usually adhering to the letter of the law. Sponsors of orphan products have used several techniques to exploit the act. In one common practice, sponsors apply for orphan drug designations, and therefore marketing exclusivity, for a narrow indication, although a wide "offlabel" market for other indications may exist or is likely to develop. In a

\footnotetext{
635 U.S.C. $\$ 156$.

${ }^{7} 26$ U.S.C. $\$ 28 ; 26$ CFR $\$ \$ 1,28-1,1.28$ OC-3.
} 
related practice, sponsors stack seven-year monopolies for the same drug on top of each other for indications that differ only negligibly. Another, less common, practice is to seek orphan designations for drugs that are barely modified versions of existing orphans and that offer little additional therapeutic improvement. Finally, as we will describe, there is the common practice of fragmenting patient populations into artificial patient subgroups in order to avoid the 200,000 patient limit.

Burroughs Wellcome, the manufacturer of zidovudine (AZT), illustrates some of these practices. In 1985, the company applied for orphan drug status for AZT to treat what was then being called AIDS-related complex (ARC). AZT had already been designated an orphan to treat AIDS, which affected fewer than 200,000 Americans at that time, but because the FDA believed that ARC affected more than 200,000 people, it asked Burroughs Wellcome to submit information required under the law about the costs of developing and distributing AZT (Fredd 1985). The company declined to do so. Two years later, however, Burroughs Wellcome received an orphan designation for the use of AZT in the advanced $A R C$ subpopulation, despite complaints by Ellen Cooper, then head of the FDA's antiviral division, that the company was fragmenting the total ARC population into arbitrary subgroups (Cooper and Stanley 1987).

A similar example is zalcitabine (ddC). In 1988, Hoffman LaRoche requested orphan drug status for $\mathrm{ddC}$ for persons with ARC. Again, noting questions about the prevalence of ARC, the FDA deemed the application incomplete. Hoffman LaRoche responded by limiting its request to the treatment of full-blown AIDS, rather than ARC or HIV-related disease. Hoffman LaRoche received orphan drug designation for ddC in 1988, and marketing exclusivity was granted for the treatment of AIDS in 1992. In reality, both AZT and ddC were initially used in the treatment of ARC even though the FDA had not approved such indications, making them "off-label" uses of the drugs.

Table 1 illustrates nine instances in which the same manufacturer received at least two orphan drug designations to treat closely related aspects of HIV disease. Typically, one designation is to prevent a condition and another is to treat it. In each case, the sponsor can generally use much of the same research to support both applications. Not shown in the table are the numerous instances of multiple sponsors receiving orphan designations for the same drug to be used in treating the same HIV-related condition. 
TABLE 1

Multiple Orphan Drug Designations

\begin{tabular}{|c|c|c|}
\hline Drug & Company & $\begin{array}{l}\text { Orphan drug } \\
\text { designation }\end{array}$ \\
\hline Pentamidine isethionate & Fujisawa Pharmaceutical ${ }^{2}$ & $\begin{array}{l}\# 1 \text { : to treat PCP } \\
\# 2 \text { : to prevent PCP }\end{array}$ \\
\hline AZT & Burroughs Wellcome & $\begin{array}{l}\# 1 \text { : to treat AIDS } \\
\# 2 \text { : to treat ARC }\end{array}$ \\
\hline Rifabutin & Adria Laboratories, Inc. & $\begin{array}{l}\text { \#1: to prevent dissem- } \\
\text { inated MAC } \\
\text { \#2: to treat dissemi- } \\
\text { nated MAC }\end{array}$ \\
\hline Clindamycin & Upjohn Company & $\begin{array}{l}\# 1: \text { to prevent AIDS- } \\
\text { associated PCP } \\
\# 2 \text { to treat AIDS- } \\
\text { associated PCP }\end{array}$ \\
\hline $566 C 80$ & Burroughs Wellcome & $\begin{array}{l}\text { \#1: to prevent AIDS- } \\
\text { associated PCP } \\
\text { \#2: to treat AIDS- } \\
\text { associated PCP }\end{array}$ \\
\hline $\begin{array}{l}\text { Anti-CMV monoclonal } \\
\text { antibodies }\end{array}$ & Biomedical Research Institute & $\begin{array}{l}\text { \#1: to prevent human } \\
\text { CMV in persons } \\
\text { with AIDS } \\
\text { \#2: to treat human } \\
\text { CMV in persons } \\
\text { with AIDS }\end{array}$ \\
\hline HIV immune globulin & North American Biologicals & $\begin{array}{l}\# 1 \text { : to treat AIDS } \\
\# 2 \text { : to treat HIV. } \\
\text { infected women } \\
\text { and their children }\end{array}$ \\
\hline Dapsone USP & Jacobus Pharmaceutical & $\begin{array}{l}\# 1 \text { : to prevent PCP } \\
\# 2 \text { : to treat PCP }\end{array}$ \\
\hline
\end{tabular}

${ }^{2}$ Formerly Lyphomed.

Abbreviations: ARC, AIDS-related complex; CMV, cytomegalovirus; MAC, mycobacterium avium complex; PCP, Preumocystis carinii pneumonia.

A 1988 amendment to the act requires sponsors to apply for orphan drug designation before submitting a new drug application or a product license application to the FDA. ${ }^{8}$ Presumably, such an application was de facto evidence of the sponsor's belief in the drug's commercial poten-

${ }^{8}$ P.L. 100-290, 100th Cong., 2d sess. (1988). 
tial. However, there are no contingencies in place to deal with the possibility that orphan drugs will eventually have wider-than-anticipated uses or that the patient population will eventually exceed the 200,000-person threshold, as occurred with HIV disease.

Nor is there any certainty that the best of two competing products will earn exclusive marketing rights under the Orphan Drug Act. The FDA makes its awards to the first sponsor to obtain marketing approval, sometimes requesting additional studies and further documentation that the drug is safe for use in the designated orphan population. The final outcome of multiple sponsors may be unrelated to the quality of the competing products or to the date a firm actually submits its application.

The race to market is illustrated by the battle between Lyphomed and Fisons over market exclusivity for similar versions of aerosolized pentamidine, used to prevent AIDS-related Pneumocystis carinii pneumonia (PCP). Both companies were awarded orphan drug designation for the same indication within three months of one another. Fisons eventually lost out to Lyphomed, despite protests that its drug delivery system was an improvement over that of Lyphomed and that the FDA held Lyphomed to a less rigorous standard. Lyphomed was granted seven years of market exclusivity under the Orphan Drug Act for its version of the drug in 1989, which means that Fisons cannot market its drug in the United States until 1996.

In some instances, the incentives of the Orphan Drug Act may not be necessary to stimulate drug research. In the early 1980 s, five manufacturers were developing recombinant human growth hormone products, used to treat hypopituitary dwarfism in children. Apparently, these companies were convinced that the product had commercial potential even without government subsidies (Wiggans 1990; U.S. Congress 1990). Nonetheless, Genentech and Eli Lilly were willing to exploit the benefits of the act after receiving orphan designations for their somewhat different hormone products. Whereas Genentech enjoyed market exclusivity under the act, Eli Lilly shared in the lucrative market because it was also awarded orphan drug exclusivity based upon the FDA's determination that its product was structurally different from Genentech's. (Exclusivity provisions for human growth hormone have recently expired for both companies.)

Contrary to its intent, the Orphan Drug Act has, in many instances, failed to prod industry into conducting research into diseases that affect small numbers of people. For the purposes of this article, we examined 
the HIV-related drugs with orphan designations. As of May 1994, 90 percent of such research clustered around HIV-related conditions with at least four orphan designations. These were concentrated among antivirals used to prevent or treat HIV illness (25 percent), which are likely to be used by most HIV-infected persons, or drugs for PCP prophylaxis or treatment (17 percent), which remains the leading killer of people with HIV, despite the existence of effective drugs. By contrast, pharmaceutical manufacturers have paid relatively little attention to drugs for the opportunistic infections that affect smaller HIV subpopulations. There are no orphan drug designations for many of the rare pathogens associated with HIV. The major areas of HIV-related orphan drug activity are listed in table 2 .

Further, the market for treating HIV-infected people before they develop full-blown AIDS is considerably larger than the market for persons suffering end stage disease only. Until 1993, when the number of persons with CDC-defined AIDS formally surpassed 200,000, it was worthwhile for sponsors to obtain an orphan drug designation for AIDS, but to sell it "off-label" to treat the wider market of HIV-infected individuals - and they have. This abuse of the Orphan Drug Act may contribute to the cluster of designations indicated for the treatment of AIDS rather than for the rarer HIV-related diseases.

TABLE 2

Major Areas of HIV-Related Orphan Drug Activity

\begin{tabular}{lc}
\hline HIV/AIDS condition or symptom & $\begin{array}{c}\text { Orphan drug } \\
\text { designations (no.) }\end{array}$ \\
\hline Antiviral treatment of HIV disease & 17 \\
Pneumocystis carinit pneumonia & 12 \\
Diarrhea, wasting, weight loss, catabolism & 9 \\
Neutropenia or anemia & 5 \\
Toxoplasmosis gondii encephalitis & 5 \\
Kaposi's sarcoma & 5 \\
Tuberculosis & 5 \\
Cytomegolavirus & 4 \\
Other (<4 designations each) & 7 \\
Total & 69 \\
\hline
\end{tabular}


The pattern of AIDS-related orphan drug activity seriously challenges the claim that the Orphan Drug Act has spurred true innovation in the development of AIDS drugs. Many of the designated AIDS orphan drugs have been tested or approved for other uses, and few are new chemical entities. Nominal or moderate improvements over existing therapies for AIDS appear to be the rule rather than the exception. For HIV - and perhaps future epidemics as well - this casts doubt not only upon the Orphan Drug Act as presently structured, but also on the underlying need for marketing exclusivity as an incentive.

\section{The Costs of Orphan Drugs}

When Congress passed the Orphan Drug Act, the prospect that orphan drugs could become highly profitable was never seriously considered. To the contrary, the testimony that led to the passage of the act, the statutory language itself, and the subsequent debate over various amendments all implied that limited profitability was a defining characteristic of orphan drugs.

AIDS, however, helped to change that story. Burroughs Wellcome had exclusive marketing rights to AZT through 1994 under the Orphan Drug Act and a use patent from the U.S. Patent and Trademark Office that extends its monopoly to the year 2005. (Burroughs Wellcome received its American patent [ $\$ 4,724,232]$ for AZT in February 1988.) Despite reductions in price, initially set at $\$ 10,000$ per patient per year, and a lowering of the recommended drug dosage, AZT has generated more than $\$ 2$ billion in sales through mid-1994 (Wellcome plc 1992, 1993, 1994). An internal company document indicated that Burroughs Wellcome believed that orphan drug exclusivity would be financially beneficial ("a premium price could be paid because of exclusivity ..."), which may have been a factor in its decision to seek orphan drug protection (Health News Daily 1993). In the case of pentamidine, which has generated several hundred million dollars in sales for the treatment and prevention of PCP, Lyphomed increased its price by 400 percent over a three-year period after orphan designation was conferred and as clinical trials showed the increased efficacy of the aerosolized form (Arno and Feiden 1992).

AIDS is not unique in illustrating the defects of the Orphan Drug Act. Although the act presumes limited profitability, it does not require 
that it be demonstrated. Absent that requirement, the ODA has been used to increase the marketing advantages of a drug that would have enjoyed sufficient potential profitability from its patent exclusivity alone. Furthermore, a competitor seeking to invalidate marketing exclusivity for a drug with both orphan and patent protection has to be prepared to defeat both legal monopolies.

Another blockbuster success has been recombinant human Erythropoietin (EPO), a biotechnologically derived drug for treating anemia, with total sales of approximately $\$ 400$ million annually (U.S. Congress 1992a). To gain orphan drug exclusivity, the total EPO population has been segmented into narrow indications as companies seek to share in a market with the estimated potential of $\$ 2$ billion (Wiggans 1990). As of September 1992, four orphan drug designations were held by four different companies to treat anemias associated with chronic renal failure, cancer, arthritis, and HIV infection (Coster 1992; Schmergel 1990).

Legislators had also not anticipated the high prices charged for orphan drugs. Today, patients with Gaucher's disease, a rare hereditary disorder, face initial (albeit declining) yearly costs as high as $\$ 550,000$ in order to obtain Ceradase, another orphan drug and the only available treatment (U.S. Congress 1992b). Patients with severe combined immunodeficiency must pay between $\$ 100,000$ and $\$ 200,000$ annually for Adagen, the only treatment that can keep them alive (Meyers 1993). A major difference between the two, however, is that Ceradase has a market of several thousand persons while Adagen's market comprises fewer than 50 patients worldwide, making the latter's total sales truly of limited commercial value. Nonetheless, both sums are out of reach for persons with limited or inadequate insurance. Even people with prescription drug coverage find the prices a severe economic burden.

To some extent, orphan drug prices are part of a larger problem centered around the rising cost of all prescription drugs in the United States. Approximately half of all pharmaceutical expenditures are paid out of pocket (U.S. Congress 1993). Even individuals whose insurance provides coverage may face substantial copayments and deductibles. Employer-based group plans, which are the most prevalent form of private insurance, frequently require a 20 percent copayment and have a lifetime benefits cap of $\$ 1$ million (Gabel et al. 1990). With the cost of some orphan drugs reaching tens or hundreds of thousands of dollars per year, copayments can be impoverishing. Many individuals are faced with 
the option of obtaining life-saving medications and drawing down their lifetime benefits. In cases where the whole family has a lifetime cap, one ill member may leave the rest of their family permanently without any insurance coverage. Rising drug prices and inadequate third-party reimbursement exacerbate the social and economic impact of the act. Unless major health care reform is enacted, our analysis of the Orphan Drug Act is unlikely to change.

The public sector also faces large and growing costs. Federal and state spending on pharmaceuticals under the Medicaid program amounted to $\$ 6.7$ billion in 1992 (and this does not include medications prescribed in hospitals) (Pear 1993). Medicaid expenditures on pharmaceuticals have been felt particularly at the state level: drug outlays for states with drug benefits rose 224 percent between 1980 and 1988; between 1984 and 1988, drug expenditures in the average Medicaid plan grew by 75 percent, and spending more than doubled in ten states (Pryor 1990).

Setting aside the burden placed on patients and third-party payers, monopoly profits are a clear violation of the spirit and intent of the Orphan Drug Act. A number of factors render orphan drugs profitable despite the small patient population they serve. The size of the potential market may increase when a product is discovered to have value for other diseases or when the patient population grows significantly. If the drug commands an unusually high price or needs to be used frequently, over a long period of time, or at unusually high doses, a sponsor also stands to gain. For example, even with only 2,000 to 3,000 patients potentially benefiting from Ceradase, Genzyme could ultimately gross $\$ 300$ million a year in drug sales (Thompson 1991).

Despite the sales record of some orphan drugs, industry has claimed that seven-year market exclusivity and, in certain cases, high prices, are necessary to recoup the R\&D costs of orphan drugs. However, the sales of a number of orphan drugs far exceed the R\&D costs, in several cases during the first year or two that the drug has been on the market (fig. 1).

We cannot be sure how to allocate the R\&D costs between unsuccessful and successful drugs because of the unwillingness of drug companies to share information other than self-generated cost estimates, which must be accepted at face value (DiMasi et al. 1991). Furthermore, because the original intent of the orphan drug legislation was to stimulate the production of drugs with limited commercial potential, it is debatable whether the price of orphan products should bear the R\&D costs of un- 


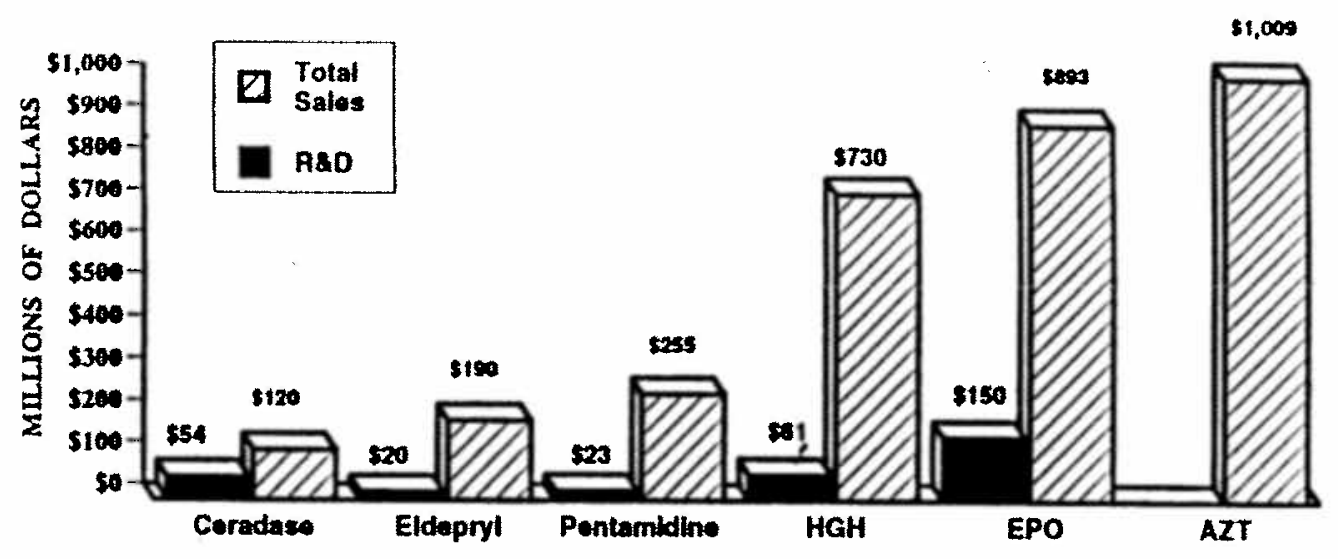

FIG. 1. Estimated total sales through 1991 versus $R \& D$ costs for selected orphan drugs. Data on all drugs (except AZT) are based on a study conducted by the Subcommittee on Antitrust, Monopolies and Business Rights, Committee on the Judiciary, U.S. Senate, and presented at hearings on January 21, 1992. AZT sales figures are derived from Wellcome plc (1991). Ceradase: manufactured by Genzyme and approved by FDA in April 1991; Eldepryl: manufactured by Somerset and approved by FDA in June 1989; aerosolized pentamidine: manufactured by Fujisawa and approved by FDA in June 1989; human growth bormone $(H G H)$ : manufactured by Eli Lilly and Genentech. (Eli Lilly's version was approved by FDA in March 1987: development costs - $\$ 16$ million; estimated sales through $1991-\$ 150$ million. Genentech's version was approved by FDA in October 1985: development costs $-\$ 45$ million; estimated sales through 1991 $\$ 580$ million.) Erythropoietin (EPO): manufactured by Amgen and approved by FDA in June 1985; zidovudine (AZT): manufactured by Burroughs Wellcome and approved by FDA in March 1987 (development costs not available).

successful drugs. Further aggravating the problem is the government's substantial participation in funding drug development, including orphan drugs (Love 1993).

There are a number of reasons to believe the cost of developing orphan drugs is less than the cost of developing other drugs. Lower development costs may result from shorter testing periods in clinical trials that are necessarily small and thus less expensive than trials of drugs for common diseases. Where drugs have already been investigated for other uses, it may not be necessary to repeat tests in animals or healthy humans, which can shave several years and millions of dollars from the development process. In the case of life-threatening conditions, the FDA has a number of mechanisms to speed the clinical testing process and make swift approval decisions (Federal Register 1988, 1990). Overall, or- 
phan drugs take 10 to 11 months less time to pass through the regulatory system than do nonorphan drugs (Farley 1988).

Intravenous pentamidine provides an example of the truncated development process. Lyphomed was excused from conducting the usual clinical trials because previously published studies had long since demonstrated the drug's safety and effectiveness (Hughes 1977), and its new drug application was approved in just six months. In October 1984 intravenous pentamidine became the first AIDS drug granted market exclusivity under the Orphan Drug Act.

Although much of this discussion has addressed the obvious problem of statutory abuse, it has ignored an equally important, but less obvious, challenge: why are the abnormally high returns needed if the free market is working? In other words, the problem of statutory abuse becomes the sole problem only if we unquestioningly accept a more fundamental problem: pharmaceutical companies that have become habituated to relatively high profits because their normal stock in trade is protected by the patent monopoly. For the past six years (1988-93), the pharmaceutical industry was the single most profitable of all the Fortune 500 industries and has ranked either first or second in 29 of the past 37 years (Fortune 500 1958-93). It would be an intolerable corporate decision, one immediately rejected by stockholders and the market generally, therefore, to invest in activities that bring a return below the industry (monopoly) average. Although the answer to this fundamental problem is necessarily speculative, certainly an industry accustomed to higherthan-competitive profits caused by patent exclusivity may be averse to the relatively lower returns of a truly competitive market. The current practices of the pharmaceutical industry may be the inevitable result of an economic sector freed from many of the dictates of normal competitive pressures.

\section{Attempts at Reform}

The growing recognition that the Orphan Drug Act has been utilized for the wrong purposes has sparked debate and a number of suggestions for reform, although recent legislative proposals have been defeated. In 1990, Congressman Henry Waxman proposed a simultaneous development provision that would have allowed competition when two or more com- 
panies were developing a drug concurrently. ${ }^{9}$ This was based on the assumption that if two or more companies were developing the same orphan drug, the drug probably was not of limited commercial value. Although such a solution is foreign to intellectual property generallycertainly in patent law -it has counterparts in particular areas, especially in trademark law where concurrent registrations, usually divided along geographic borders, are sometimes allowed for equitable reasons. ${ }^{10}$ This bill passed both houses of Congress but was pocket vetoed by President Bush. However, the experiences of Genentech and Eli Lilly, who share a $\$ 250$ million dollar annual market for human growth hormone, which costs patients between $\$ 10,000$ and $\$ 35,000$ per year, suggest that shared exclusivity may be insufficient to lower orphan drug prices. This is certainly counterintuitive and implies imperfections in the pharmaceutical marketplace, many of which may be unidentified. One example would be extensive advertising campaigns, which may distort market forces.

Another proposal was a windfall profits tax on orphan drugs during the seven-year period of market exclusivity. In 1990, 1991, and 1993, Congressman Pete Stark introduced legislation that would have taxed profits after R\&D costs had been recouped and a 25 percent profit had been earned. Another proposal, advanced by Senators Howard Metzenbaum and Nancy Kassebaum in 1992, was to impose a sales ceiling on market exclusivity. Under this legislation, monopoly protection would be withdrawn once cumulative sales reached $\$ 200$ million. None of these amendments passed.

Other ideas for reform were sent to the FDA during the period of public comment that followed publication of the agency's proposed orphan drug regulations. One suggestion was that lower cost be considered an improvement in patient care so that a second orphan drug designation could be made for a product similar to an existing one. ${ }^{11}$ Although the FDA rejected that idea, citing its lack of authority over pricing, the FDA does have regulatory authority to administer the act and could promulgate regulations that are more in the spirit of the original legislation. Most recently, legislation proposed in 1994 would require that an orphan drug's potential for commercial success be evaluated after four

\footnotetext{
${ }^{9}$ H.R. 46381990.

${ }^{10} 15$ U.S.C. $\$ 1052$ (d). See in re Beatrice Foods 429 F.2d 466 CCC.P.A., 1970.

11 See note 5.
} 
years of marketing exclusivity to determine whether exclusivity should be extended for an additional three years. ${ }^{12}$ The definition of commercial success would be deferred to the Secretary of the Department of Health and Human Services until regulations were published. The proposed amendment is seen as a compromise among interested parties, especially because there is no retroactivity, which means it would not apply to drugs already on the market or in the orphan drug pipeline. It would, however, require manufacturers to calculate the drug's target population size three years in advance, potentially precluding drugs for contagious epidemic diseases, like AIDS, from obtaining orphan status. This provision is based on the assumption that a mushrooming market is sufficient economic incentive to develop a drug without the protection of the Orphan Drug Act.

Any of these legislative changes in the act would have been consistent with our recommendations, but they provide only marginal improvements over the current state of affairs. The outcome of the 1994 congressional elections makes substantial legislative changes in the Orphan Drug Act unlikely.

\section{Conclusion}

The controversies surrounding the Orphan Drug Act are a reflection of the crisis in health care in general and that posed by the pricing practices of the pharmaceutical industry and by drug reimbursement policies of third party payers in particular. If pharmaceuticals become more, widely covered by insurance plans, public and private, access problems caused by high prices will become less severe. However, for budgetary reasons, it is unlikely that insurance coverage will be significantly broadened without the introduction of some pricing constraints. One could certainly argue that in the case of those drugs that have been developed with substantial investment of tax dollars, either through governmentsupported research, tax credits, or other public subsidies-apparently the case for many orphan drugs - the public deserves a return on its investment in the form of affordable drugs.

Several mechanisms for achieving a more rational policy toward pricing of drugs have been developed, partly with public financing. Collab-

${ }^{12}$ S. 1981, 1994; H.R 4160, 1994. 
orative research and development agreements (CRADAs) have been used between pharmaceutical manufacturers and the federal government. A few have even included a "reasonable pricing" provision in the agreement. These clauses are attacked as vague, but they could easily be enforced as they are, or tightened up and enforced with more rigor and confidence. The former director of the National Institutes of Health $(\mathrm{NIH})$ argued that it had not enforced these clauses, in part, because of the pharmaceutical industry's resistance to opening their books and the NIH's lack of expertise in conducting such an analysis (Healy 1993). Nonetheless, it is clear that "reasonable price" clauses imply the promise of enforcement.

Another proposed approach for dealing more equitably with the transfer of federal technology is to require the private sector to pay royalties to the government to compensate for its investment. However, this skirts the issue of fair pricing. Their past record makes it safe to assume that most companies will simply further inflate their prices to cover the additional expense of royalties.

A more effective solution might be to eliminate government-granted monopolies under many circumstances, starting with the presumption of exclusive licenses as the norm. This would be consistent with the American commitment to free market ideals. Ironically, it is also the principle that we attempt to impose upon less developed countries as the solution to their economic and health care problems. At present, American pharmaceutical companies are not regulated like other government monopolies, such as the public utilities, even though their products may be necessary for life. If the industry wishes to remain unregulated, it should be required to compete in the free market instead of relying on the artificial protection of government-granted monopolies. If it cannot or will not abide by competitive principles, then the public interest demands that its monopolies be regulated as they are in most other industrialized nations.

We suggest that the federal government grant a monopoly under two circumstances for drugs developed with public subsidies:

1. If it can be demonstrated that monopoly pricing and profits are needed to offset an extraordinary investment required to bring a new drug to market (a situation, however, that seems more than adequately addressed by existing patent law).

2. If the potential market for the drug is so small that no company is willing or able to invest the requisite resources in R\&D. 
In the latter case, the quid pro quo for the monopoly must be price and/or profit constraints, just as if the government itself, instead of indirectly sponsoring the drug through an orphan products program, were producing the drug directly. Neither of these conditions prevailed for AZT, pentamidine, and many other AIDS and non-AIDS-related orphan drugs. These circumstances are in fact what the original orphan drug legislation was meant to address, but fulfillment of this aim has been circumvented by many in the industry.

Where these circumstances do not exist, the government should grant nonexclusive licensing agreements when it has been substantively involved in the development of a new drug. The resulting competition makes a lower drug price far more likely, and in fact would apply as broadly as government support extends. For "true orphans" with limited commercial potential, competition is unlikely to occur.

There is no question that the Orphan Drug Act has stimulated the development of many important drugs, and most are true orphans. According to one study, three-quarters of licensed orphan drugs generated less than $\$ 10$ million in their first year of marketing (Shulman et al. 1992). Nevertheless, the abusive pricing behavior and lucrative profits of a few companies have helped to focus public attention on the reasons why the Orphan Drug Act must be reformed before its future is further jeopardized.

\section{References}

Arno, P.S., and K.L. Feiden. 1992. Against The Odds: The Story of AIDS Drug Development, Politics \& Profits. New York: Harper Collins.

Asbury, C.H. 1985. Orphan Drugs: Medical Versus Market Value. Lexington, Mass.: Lexington Books.

Colton, K.H., and M.W. Haas. 1992. Patent Law Developments in the United States Court of Appeals for the Federal Circuit during 1992. American University Law Review 42:909,986.

Cooper, E., and G.R. Stanley. 1987. Conversation between Ellen Cooper, MD, Antiviral Group Leader, HFN-815, and George R. Stanley, MD, Orphan Products Development, FDA, April 16. (memo obtained under Freedom of Information Act)

Coster, J. 1992. Recombinant Erythropoietin: Orphan Product with a Silver Spoon. International Journal of Technology Assessment in Health Care 8:635-46. 
DiMasi J.A., R.W. Hansen, H.G. Grabowski, and L. Lasagna. 1991. Cost of Innovation in the Pharmaceutical Industry. Journal of Health Economics 10:107-42.

Farley, D. 1988. How the FDA Approves New Drugs. ASM News 54:666-75.

Federal Register. 1988. Investigational New drug, Antibiotic, and Biological Drug Product Regulations; Procedures for Drugs Intended to Treat Life-Threatening and Severely Debilitating Conditions. 53: 41516-34.

-1990. Expanded Availability of Investigational New Drugs Through a Parallel Track Mechanism for People with AIDS and HIV. Related Diseases (proposed rules). May 21:20856-60.

Food and Drug Administration. 1984. Interim Guidelines for Obtaining Designation of a Drug as an Orphan. Washington: Office of Drug Products Development.

-1994a. Drugs Currently Approved by the FDA for HIV Infections and AIDS-Associated Conditions. Washington: Office of AIDS and Special Health Services. (mimeo)

- 1994b. Orphan Products Board. Cumulative list of orphan product designations and approvals through May 1994.

Fortune 500. 1958-93. Annual issues.

Fredd, S. 1985. Letter from Dr. Fredd, Office of Orphan Products Development, to Dr. G. Perkins, Associate Director of Drug Regulatory Affairs, Burroughs Wellcome, July 17. (obtained under Freedom of Information Act)

Gabel, J., S. DiCarlo, C. Sullivan, and R. Thomas. 1990. EmployerSponsored Health Insurance, 1989. Health Affairs 9:3.

Health News Daily. 1993. Burroughs' AZT '750 Patent Application Based Directly on NIH Test Results. (July 19):3-5.

Healy, B. 1993. Statement by the director, National Institutes of Health, on February 23 before the Special Committee on Aging: The Federal Government's Investment in New Drug Research and Development: Are We Getting Our Money's Worth? Washington: U.S. Senate.

Hughes, W.T. 1977. Pneumocystis carinit Pneumonia. New England Journal of Medicine 297:1381-3.

Kalinchak, S.G. 1994. Obviousness and the Doctrine of Equivalents in Patent Law: Striving for Objective Criteria. Catbolic University Law Review 43:577.

Love, J. 1993. The Other Drug War: How Industry Exploits Pharm Subsidies. American Prospect 14:121-8.

Meyers, A.S. 1991a. The U.S. Orphan Drug Act: Should the Law Cover Highly Profitable Drugs? World Pharmaceutical Standards Review 1:24-5. 
- 1991b. Letter to Peter S. Arno from the executive director of National Organization for Rare Disorders, Inc., November 12.

- 1993. Letter to Peter S. Arno from the executive director of National Organization for Rare Disorders, Inc., August 5.

Pear, R. 1993. Drug Industry Musters a Coalition to Do Battle over a Medicaid Bill. New York Times (July 7):1.

Pryor, D. 1990. A Prescription for High Drug Prices. Health Affairs 9: $101-13$.

Scharf, S.F. 1985. Orphan Drugs: The Question of Products Liability. American Journal of Law and Medicine 31:3-18.

Schmergel, G. 1990. Testimony before the Subcommittee on Health and the Environment, Committee on Energy and Commerce, February 7. Washington: U.S. House of Representatives.

Shulman, S.R., B. Bienz-Tadmor, P.S. Seo, et al. 1992. Implementation of the Orphan Drug Act. Food and Drug Law Journal 47:363-403.

Thompson, L. 1991. The High Cost of Rare Diseases: When Patients Can't Afford to Buy Lifesaving Drugs. Washington Post (June 25).

U.S. Congress. 1982. Preliminary Report of the Survey on Drugs for Rare Diseases. Prepared for the Subcommittee on Health and the Environment, Committee on Energy and Commerce. Washington: U.S. House of Representatives.

- 1990. Testimony by Novo-Nordisk Pharmaceuticals before the Subcommittee on Health and the Environment, Committee on Energy and Commerce, February 7. Washington: U.S. House of Representatives.

-1992a. Federal and Private Roles in the Development and Provision of Alglucerase Therapy for Gaucher's Disease (OTA-BP-H104). Washington: Office of Technology Assessment.

-1992b. Hearings before the Subcommittee on Antitrust, Monopolies and Business Rights, Committee on the Judiciary, January 21. Washington: U.S. Senate.

- 1993. Pharmaceutical R\&D: Costs, Risks, and Rewards (OTAH-522). Washington: Office of Technology Assessment.

Van Woert, M.H. 1978. Profitable and Nonprofitable Drugs. New England Journal of Medicine 298:903-6.

Wellcome plc. 1991. 1991 Annual Report.

- 1992. 1992 Annual Report.

- 1993.1993 Annual Report.

- 1994. Second Interim Report.

Wiggans, T. 1990. Testimony before the Subcommittee on Health and the Environment, Committee on Energy and Commerce, February 7. Washington: U.S. House of Representatives. 
Acknowledgments: This research was supported in part by grants from the Public Policy Research Program of the American Foundation for AIDS Research and from the Henry J. Kaiser Family Foundation. We would like to thank Abbey Meyers, whose dedication to the people with orphan disorders helped inspire this project, for her help and encouragement.

Address correspondence to: Peter S. Arno, PhD, Department of Epidemiology and Social Medicine, Montefiore Medical Center/Albert Einstein College of Medicine, 111 East 210 Street, Bronx, New York 10467-2490. 